- The average daily gain from birth to day of test (A.D.G.).

- The average of six backfat measurements, adjusted to $85 \mathrm{~kg}$ of liveweight using a correction factor equal to $0.2 \mathrm{~mm} / \mathrm{kg}$ (B.F.).

- A performance index combining the two above criteria (I).

An analysis of variance of the performances recorded from +659 young Large White gilts (L. W.) and from r 938 young Landrace gilts (LR) was executed considering the following nested model : Herd - Test group - Sire - litter. Heritability coefficients were estimated from sire variance components.

The values found for heritability coefficients of the 3 criteria (A.D.G., B.F. and I.) are the following :

- in $L$. W. breed : $0.52 ; 0.40$ et 0.38 respectively;

- in LR. breed : $0.29 ; 0.48$ et 0.35 respectively.

When all data together were analysed recording to the classification : Breed - Herd - etc..., the estimates obtained were : $h^{2}=0.43$ (A.D.G.), $h^{2}=0.37$ (B.F.), $h^{2}=0.35$ (Index) and $v_{\mathrm{G}}=0.06\left( \pm 0 . \mathrm{I}_{4}\right)$ for the genetic correlation coefficient between A.D.G. and B.F.

Validity of these estimates is discussed in the paper. Even if values found for heritability of backfat thickness are lower than those usually recorded from backfat measurements in testing stations, economical efficiency of "on-farm " testing of young gilts remains very important.

\title{
Comparison of french pig breeding herds for fattening and carcass characteristies
}

\author{
D. TASTU, M. MOLÉNAT, L. OLLIVIlR \\ Station de Génétique animale, I. N.R. A., C. N.R.Z., \\ 78350 Jouy en Josas
}

\begin{abstract}
A sample of I 432 female Large White and Landrace pigs, tested in 1973-1974 in five testing stations, has been analysed in order to assess the importance of herd differences and possibility to use the data to compare different breeding herds. Other factors considered were "year", "station ", "batch " and " sire ". The year effects are negligible. But important station effects exist for most carcass measurements and for meat quality, the station variance component going up to a maximum of $43 \mathrm{p}$. roo for some of these characters. The batch effects are large only for fattening and meat quality measurements. As each herd usually tests the progeny of only one boar in a given batch, the sire effects are confounded with the herd effects. Thus the genetic portion of the between-herd variance may not be estimated from this type of data. If one assumes that the major part of the herd variance is of genetic origin, it would be appropriate to compare herds on the basis of the average breeding value of their breeding animals.
\end{abstract}

